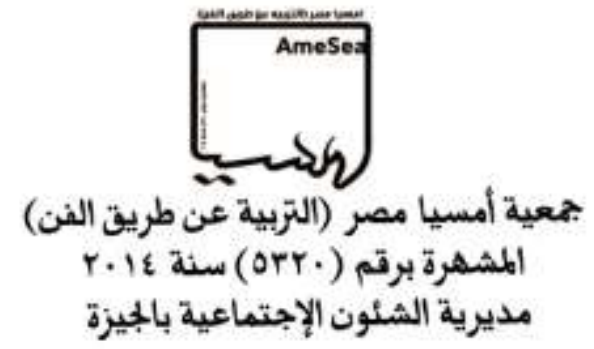

النزعة الدادية في أعهال الفن المعاصر

إعداد

م. د/ سمير فاروق حسنين

مدرس بقسم النقد والتذوق الفني

كلية الثربية الفنية - جامعة حلوان 


\section{خلفية المشكية:}

بعيش الفنان المعاصر - فى منتصف العقد الثانى من الألفية الثالثة - حياة لم تخـلـُ مـن المعاناة والألم، ورغم ذلك لم يفقد الإيمان بالتغبير و القدرة على صناعة مستقبل أفضل، من خلال نثر الثقافة وتثمية الوعي والبحث عن الحلول المستقبلية لأزمات الإنسان المعاصر؛ فيصـارع الو اقع من خلال الفن، يتحدث يغضب يثور يصرخ بسخر بفكره وترجمته للو اقع الصعب مسن حوله، الذى سادت فيه الحروب و الصر اعات و الثـائعات، فلا شيء أصــبح صــادق، لا شــيء أصبح حقبقى، لا شيء أصبح انسانى، كله عدم!!!

إنها الدادية (Dadaism) التي لم تنتهى بعد، فهى سبيل للتعبير عن كل تفاصبل معاناة الإنسان بصورها المختلفة، خصوصاً في نماتثلاتها النفية التي تنلبه الأمل في أن بصنع حلماً أو هاجساً أو حتى وهماً بعطي لحياته معنى. ومع التحو لاث الاجثماعية والسياسية والاقتصادية شديدة الوطأة، ذات التأثير ات المادية والفكرية والنفية العمبقة ظهرت الدادية الجديدة فى أوائل الستينات من القرن الماضى.

هناك فنانين معاصرين دائمى التعبير عن قضابيا الإنســان المعاصــر وأزماتــه النفسـية و الاجتماعية والسياسية و الثقافية والاقتصادية، و إفراز اتها من القلـق و الصـــر اعات و الضــباع

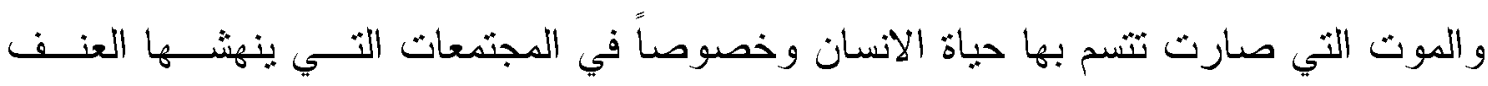
و النطرف في مستهل القرن الحادي و العثرين، وبما تتطوي عليه من اضطراب وثمزق وخديعة و إحساس بالخوف واغنراب عن المكان.

\section{مشكلة البحث: \\ تتحدد في التساؤلات التالية:}

1. هل هناك مظاهر للنزعة الدادية في أعمال الفن المعاصر؟ Y. هل تختلف مظاهر وسمات الدادية في أعمال الفن المعاصر عن مظــاهر وســـات داديــة

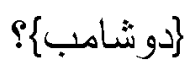
r. هل نرنبط مظاهز الدادية في أعمال الفن المعاصر بالصر اعات والنزاعات في العالم؟ كونا؟ 


\section{فروض البحث: \\ يفترض البحث الآتي:}

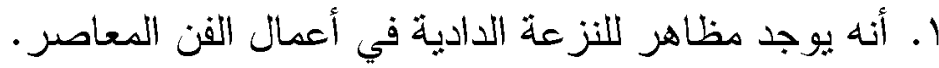

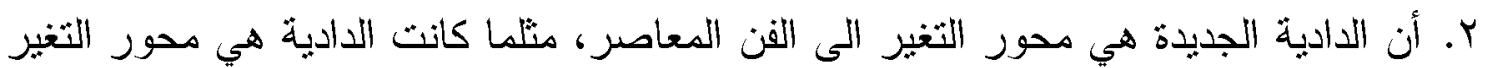
إلى فن ما بعد الحداثة.

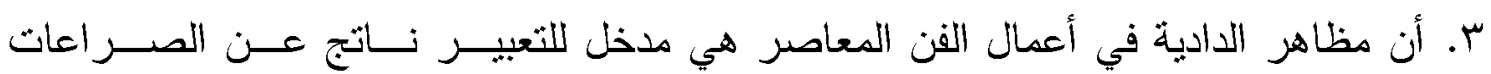
و النز اعات في العالم.

أهداف البحث:

1. الكثف عن مظاهر النزعة الدادية في أعمال الفن المعاصر.

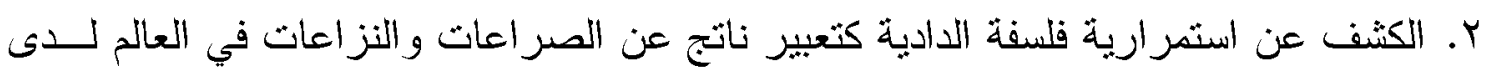

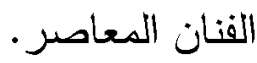
r. التأكيد على استمر ارية فلسفة الدادية كتعبير ناتج عن الصر اعات والمنازعات في العالم.

\section{أهمبة البحث:}

1. بيسهم في الإثراء العلمي والمعرفي فيما بنعلق بفلسفة الدادية.

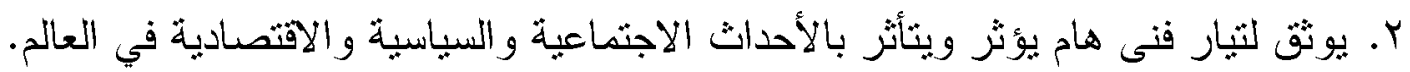

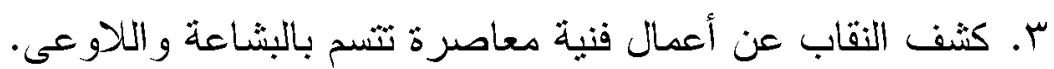
ع. رصد الاتجاهات الفنبة النى لها صفة النطور والاستمر ارية.

\section{حود البحث:}

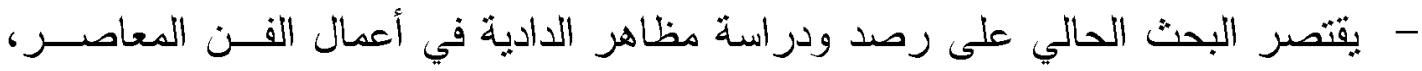
للحصول على المعلومات المطلوبة الثي نشمح بتحقيق أهداف هذه الدراسة.

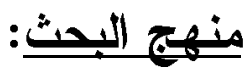

- - استخدم البحث المنهج الوصفى المقارن لملاءمثه لهذه الارساة. 


\section{ا ـ الادبية والثورة على القيم:}

تعد الحركة الدادية بمثابة تبار أدبى وفنى نشأ بعد الحرب العالمبة الأولى عام [1910]،

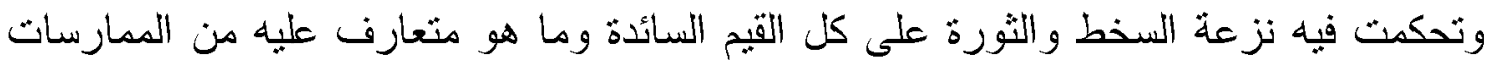

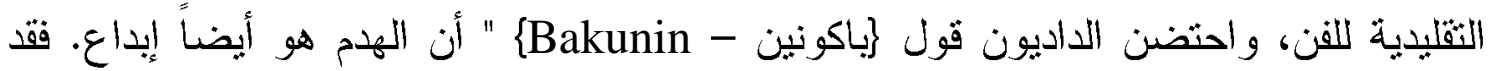

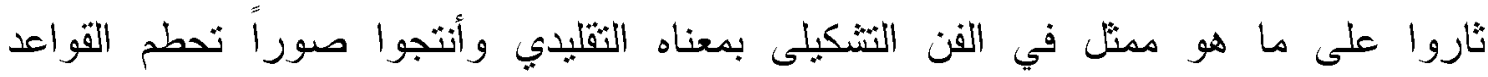
والأعراف المتفق عليها في الفن حتى ولو أدى ذلك إلى إحداث صدمة للجمهور" (البسيونى،

إن أعمال فنانو الدادية تنتهج المواضيع الني تعبر عن الصراع، وقسوة الإنسان ضد الفن

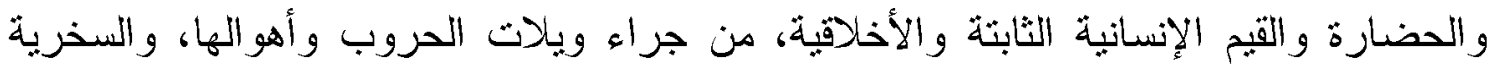

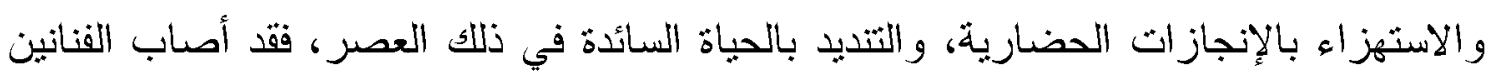

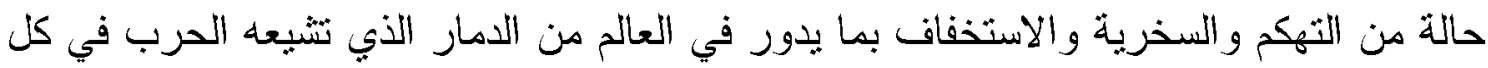
مكان، ولذلك كان رد فعل الفنانين بأن كل شيء لا يساوي شيئاً، "ولم يتبع الداديون منهجاً محدداً

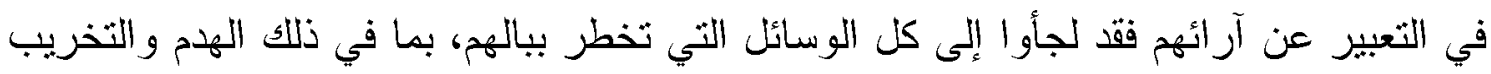

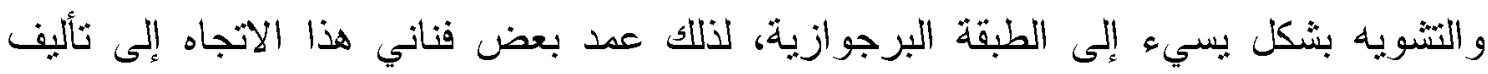
لوحات من أنثياء عادية جداً أثنارت الرأي العام لكونها غير مألوفة في المئه المجال الفني كصناديق

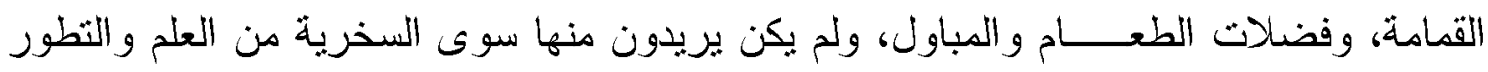

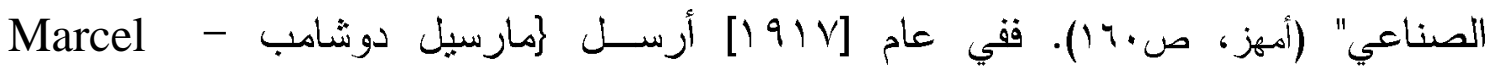

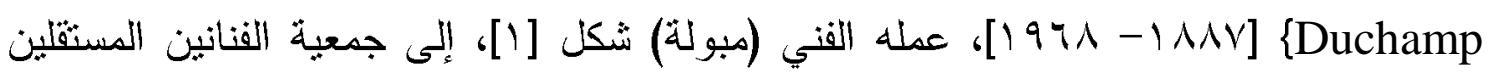

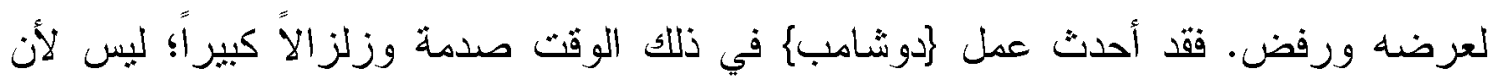

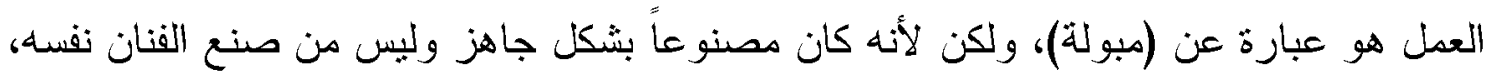

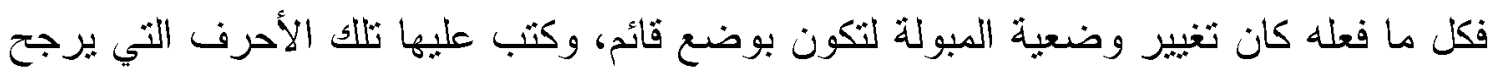
أنها تنثبر لصانعها. ثم بعد ذلك قام كدونشامب\{ عن عمد إلى إضافة شارب إلى الجيوكندا

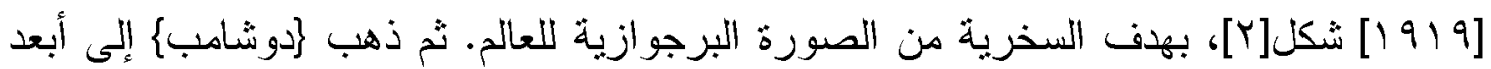

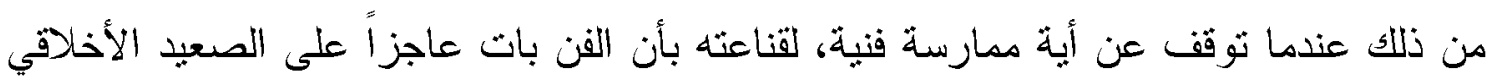

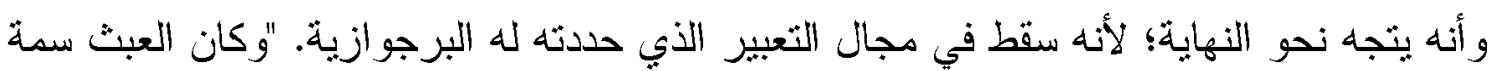

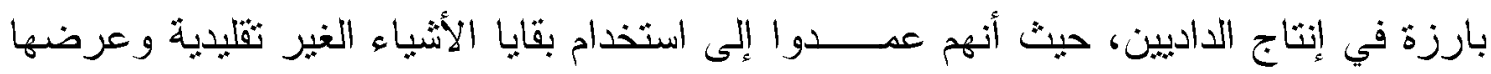


في المعارض الفنبة باعنبارها فناً مما أحدث صدمة لاى عامة الجمهور، ورفعت هذه الحركة

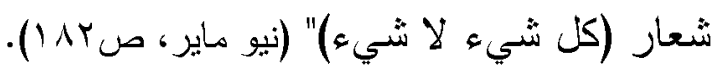

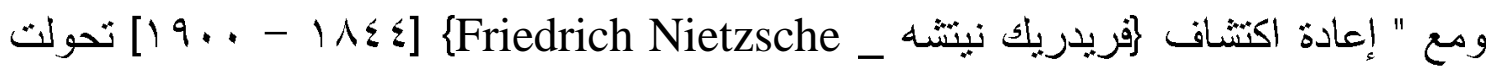
الاهنمامات الفنية من القضايا النفسية، وظهرت الدعوة إلى نسجيل الطبقات الدنبا من العقل"

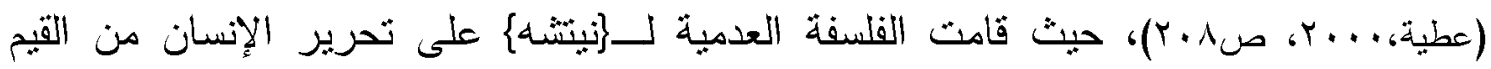

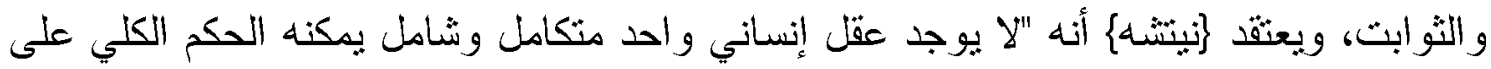

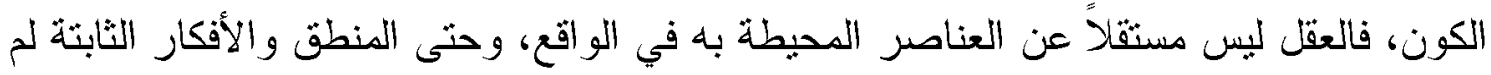

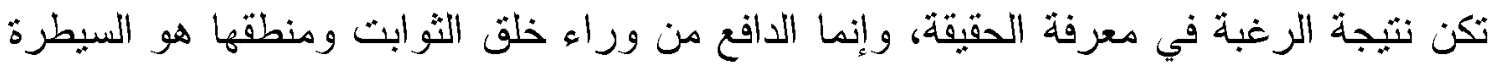

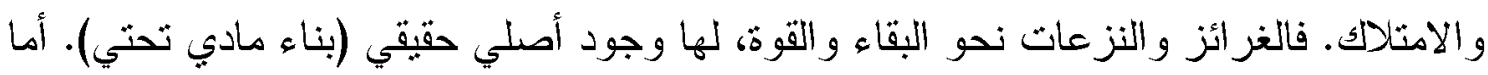

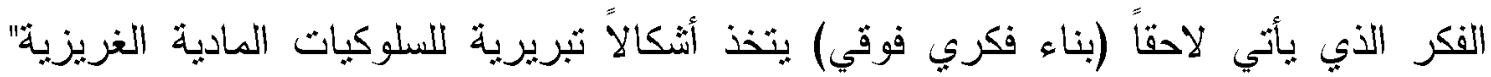

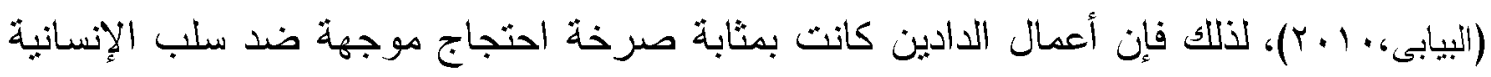

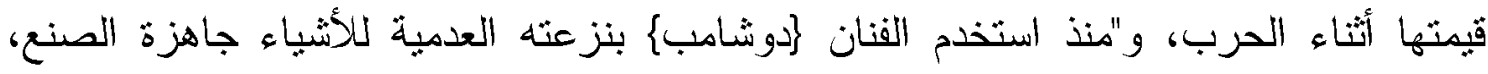

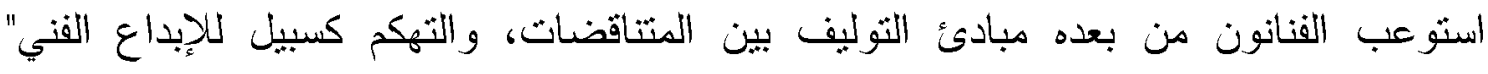

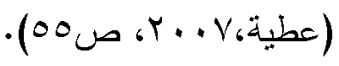

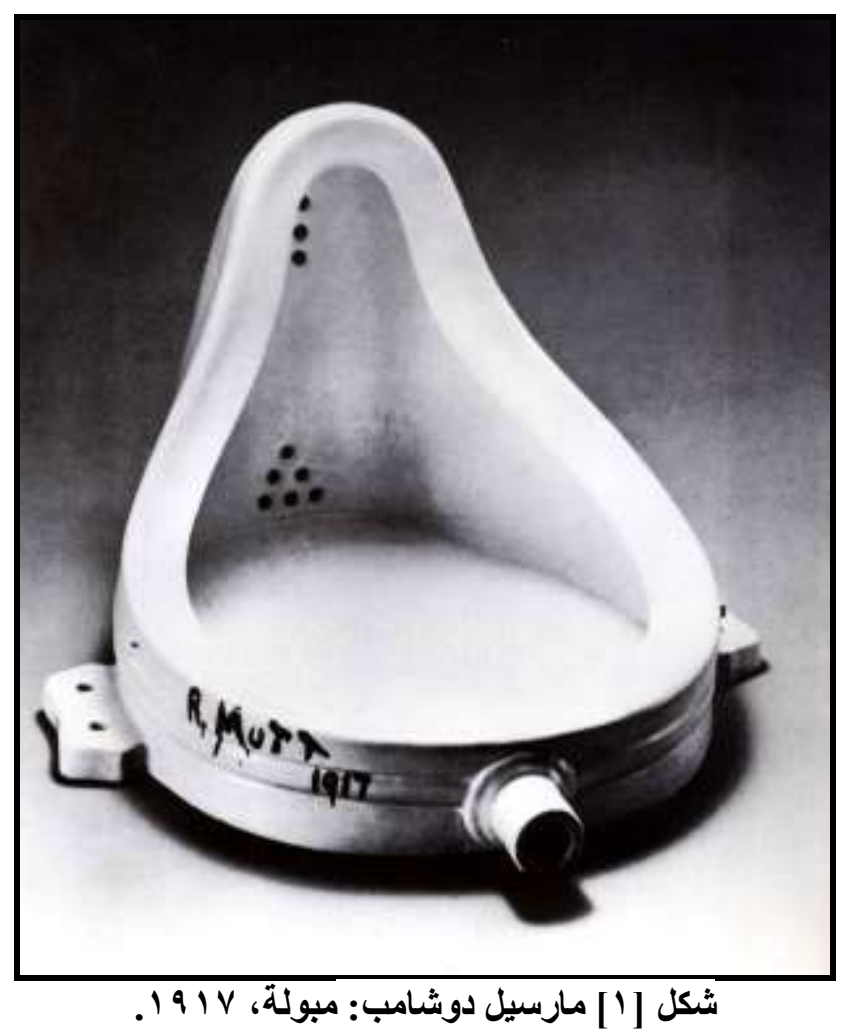




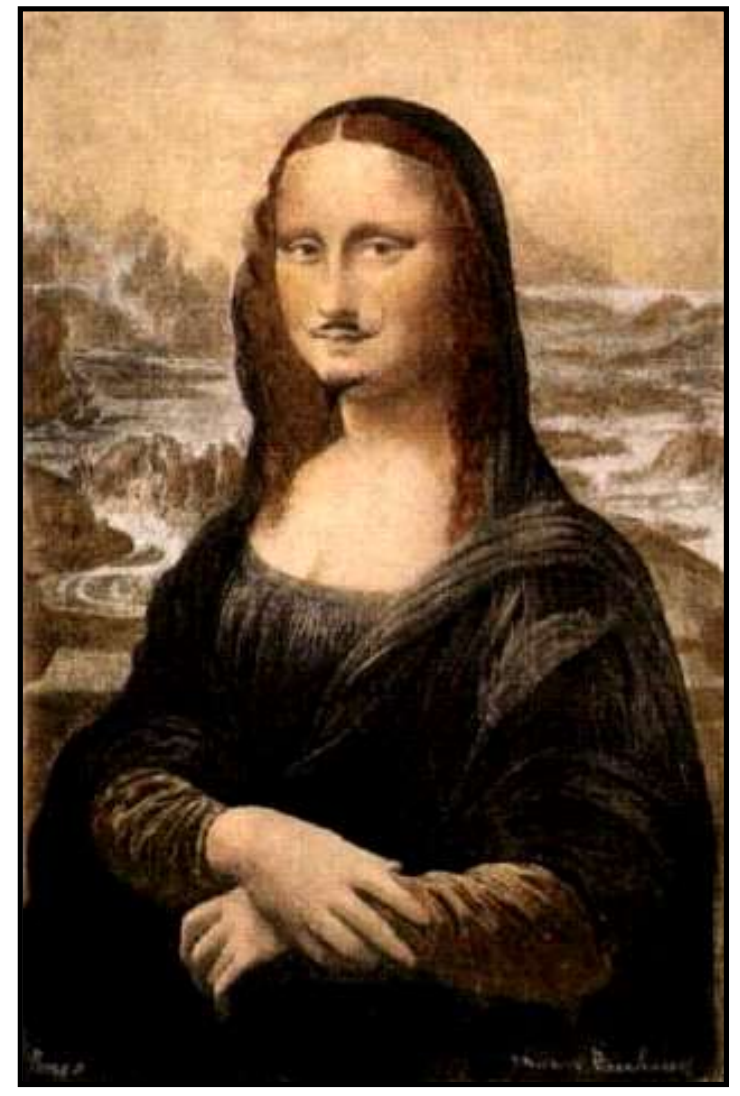

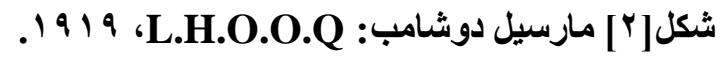

\section{r ا لاد ادبة كمردود فنمى للعرب الباردة:}

غيرت الحرب العالمبة الثانية [9 (9 19-190] الخارطة السباسية والعسكرية والبنية

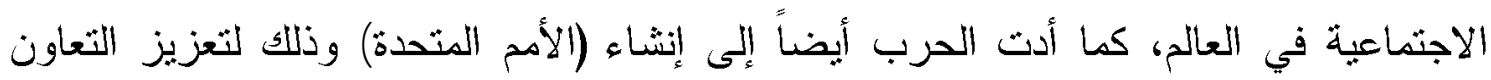

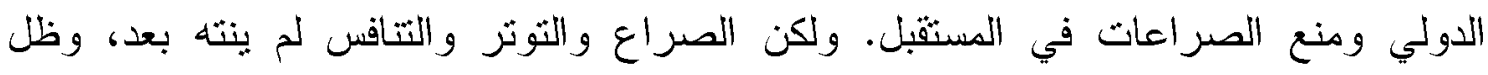

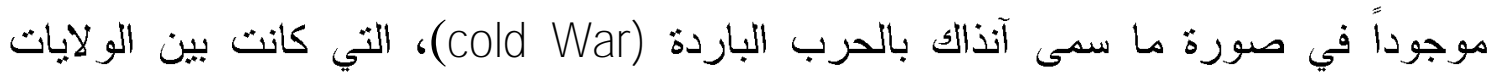

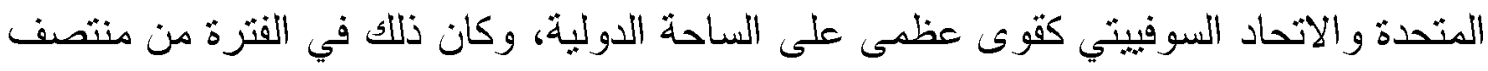

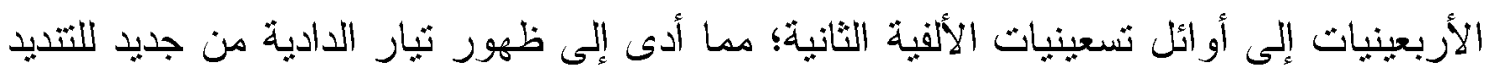

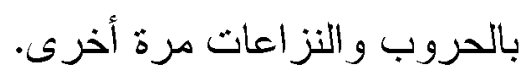

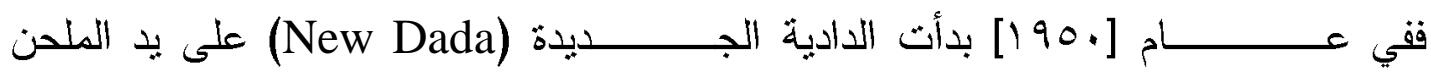

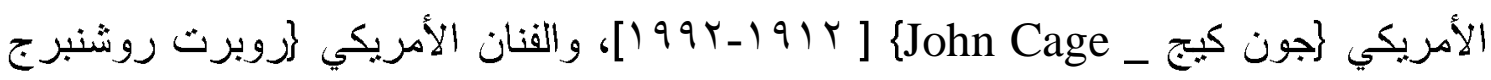

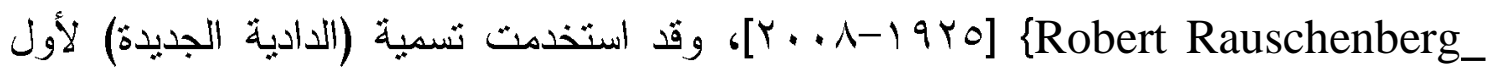




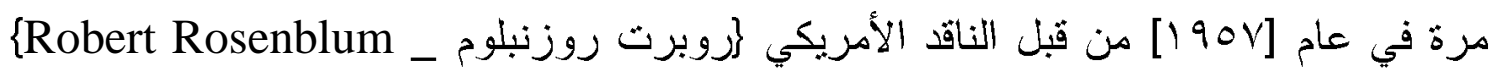

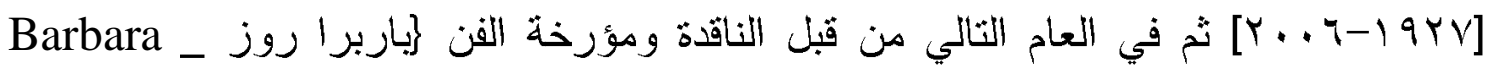

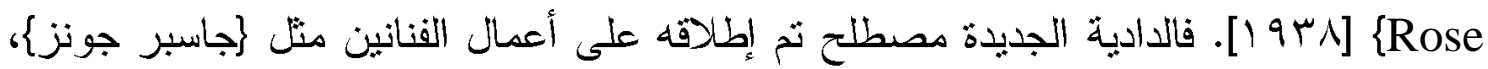
و \}روبرت روشنبرج\{، و (ألان كابراو\{، الذين بدؤا تحولاً جذريا عن التركيز على اعلى الفن الحديث خلال خمسينيات القرن الماضى. ومن المعروف عـن فنانى الدادية الجديدة استخدامهم الوسائط

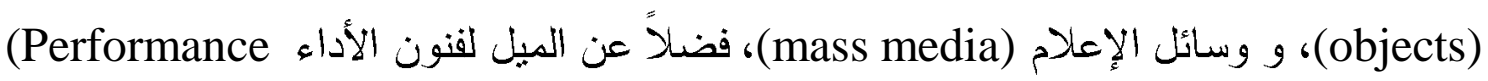
(art) وقد "تمرد هؤلاء الداديون على اللوحات الفنبة المشحونة بالعواطف من قبل التعبيريون الذين سيطروا على عالم الفن في الخمسينات، من خلال طرح موضوعات غير تقليدية ومشاهد غريبة نعنمد على الفكر والمفهوم، مما أسفر عن تثكيل تغييرات جذرية في الفن الحديث خلال الستينات ومهذ الطريق لفن البوب، و المينيمال، و المفاهيمية" (ولف، جوستين). يرنبط مصطلح الدادية الجديدة بالمفهوم العام لتبار الدادا الذى كان من قبل، وهدفها هو

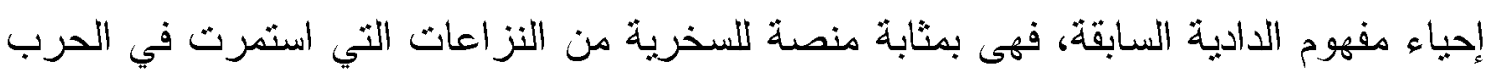

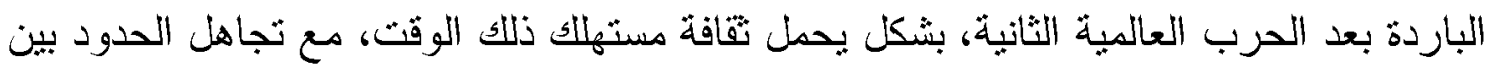

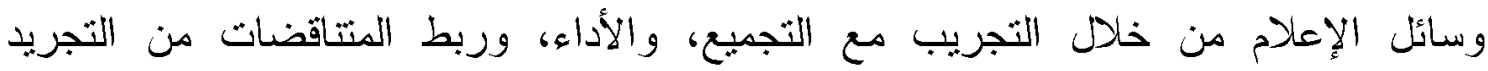

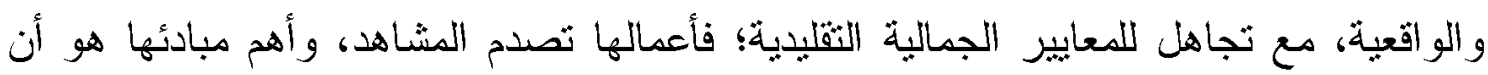
تفسير المشاهد هو الذى يحدد العمل، وليس قصد الفنان. وتؤكد الدادية الجديدة أن مفهوم الدادية

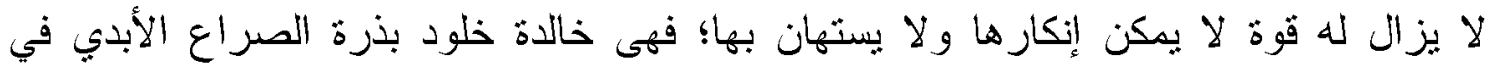
الحياة، وأكثر الأسماء البارزة لهذه الحركة هم (روشنبرج، جونز، جيم داين، جون تثنامبرلين

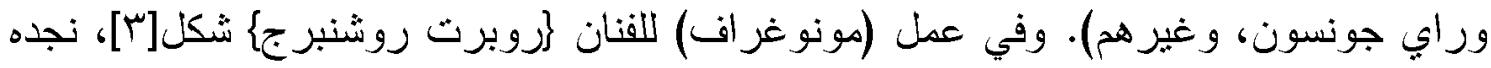

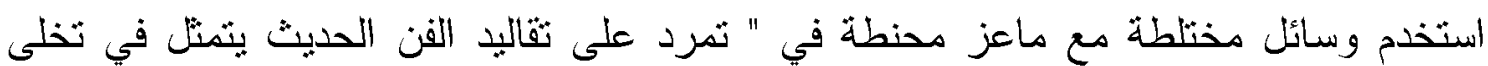

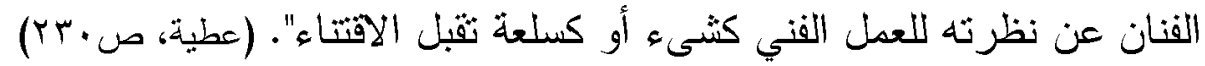

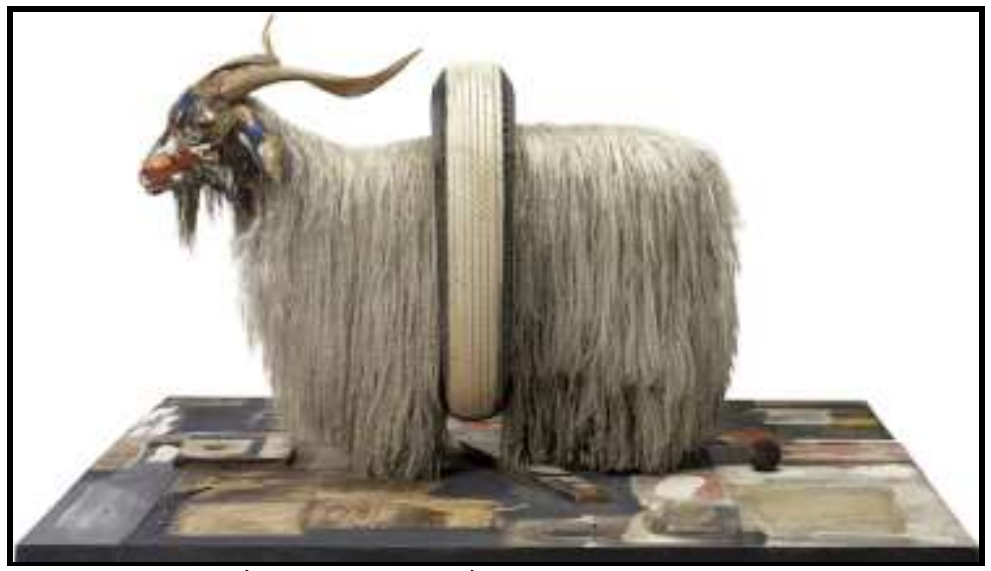

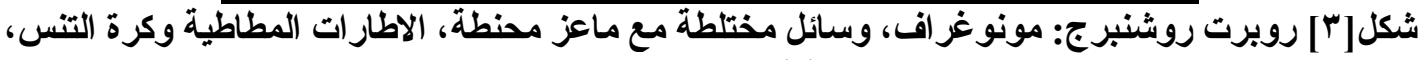

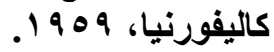


أما في عمل (مرحاض ليّن) للفنان \}كلايس أولانبرج _Claes Oldenburg

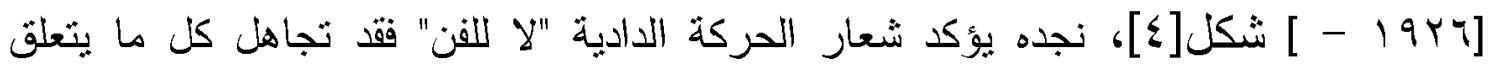

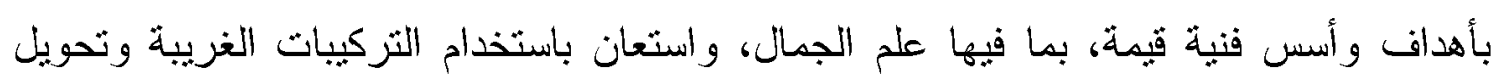

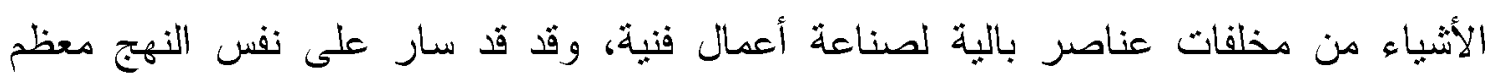

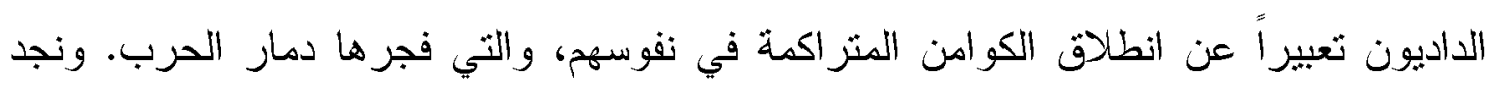

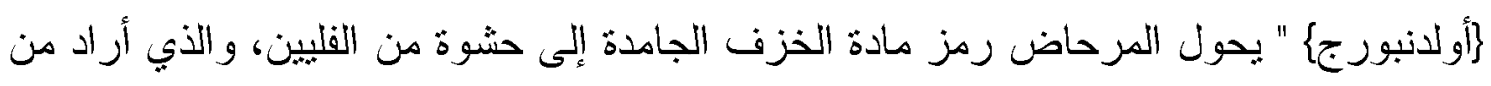

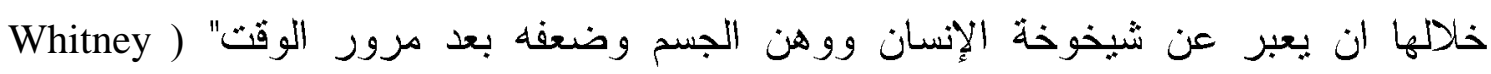
.(Museum

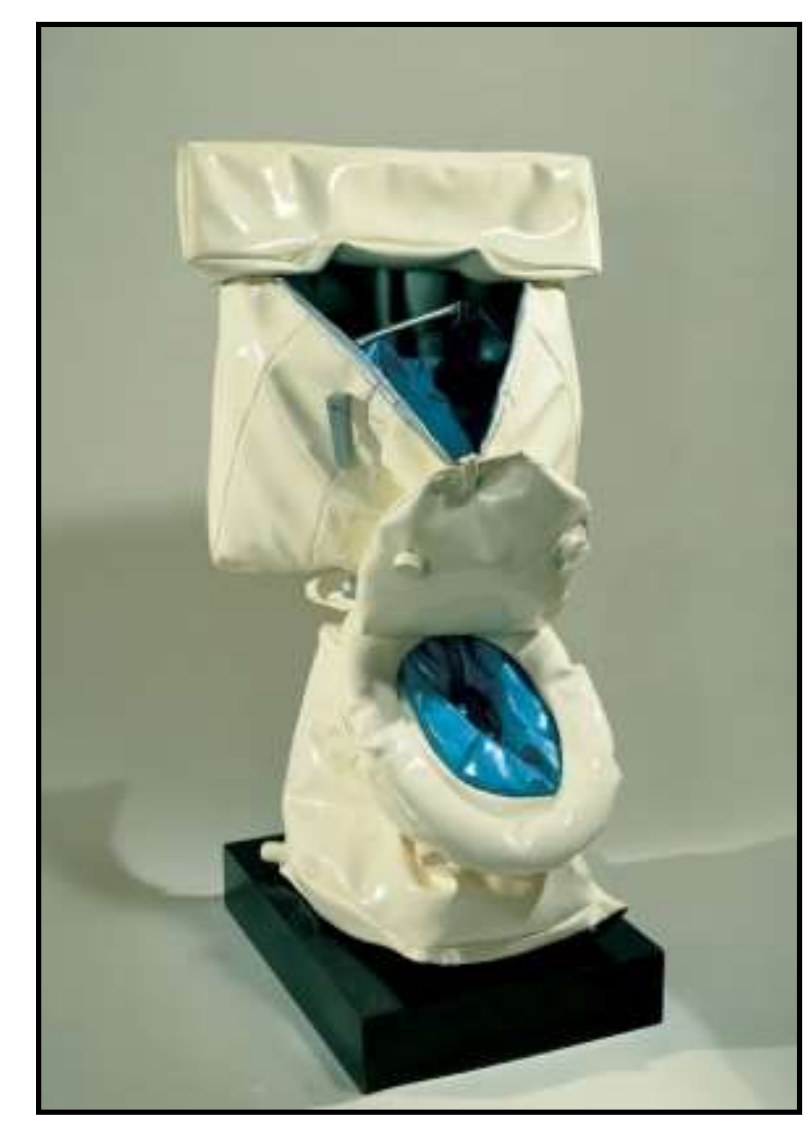

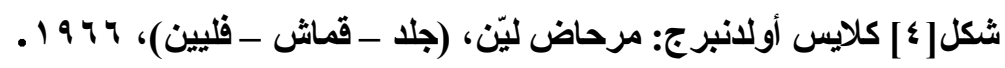

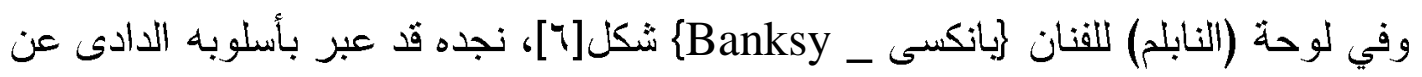

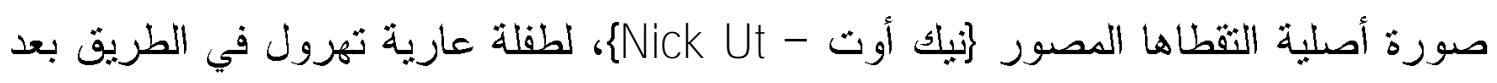

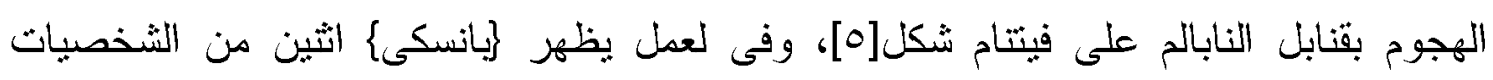
الخيالية الأمريكية الثهيرة (ميكي ماوس ورونالد ماكدونالا)، وهما بمسكان بأيدي طفلة صغيرة 
أثتاء حرب فيتنام، حين قررت أمريكا الندخل ومساعدة الفيتاميين الجنوبيين، "وكان هناك العديد

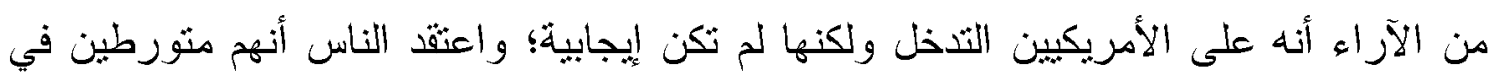
هذا الهجوم، لذلك أظهر كبانسكى\{ هذه الثخصبات الثهيرة المعروفة للترفيه عن الأطفال في

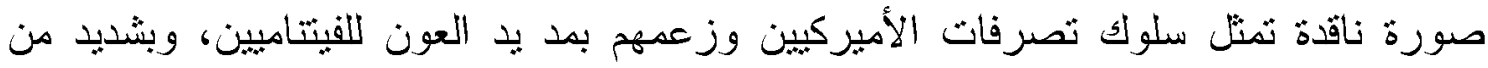

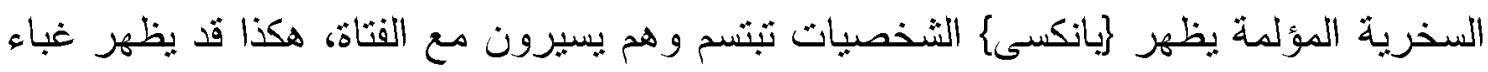
الأمريكان لأنهم أسقطو ابطريق الخطأ قنابل النابالم على أرض فينتام الجنوبية" (Bray, tim).
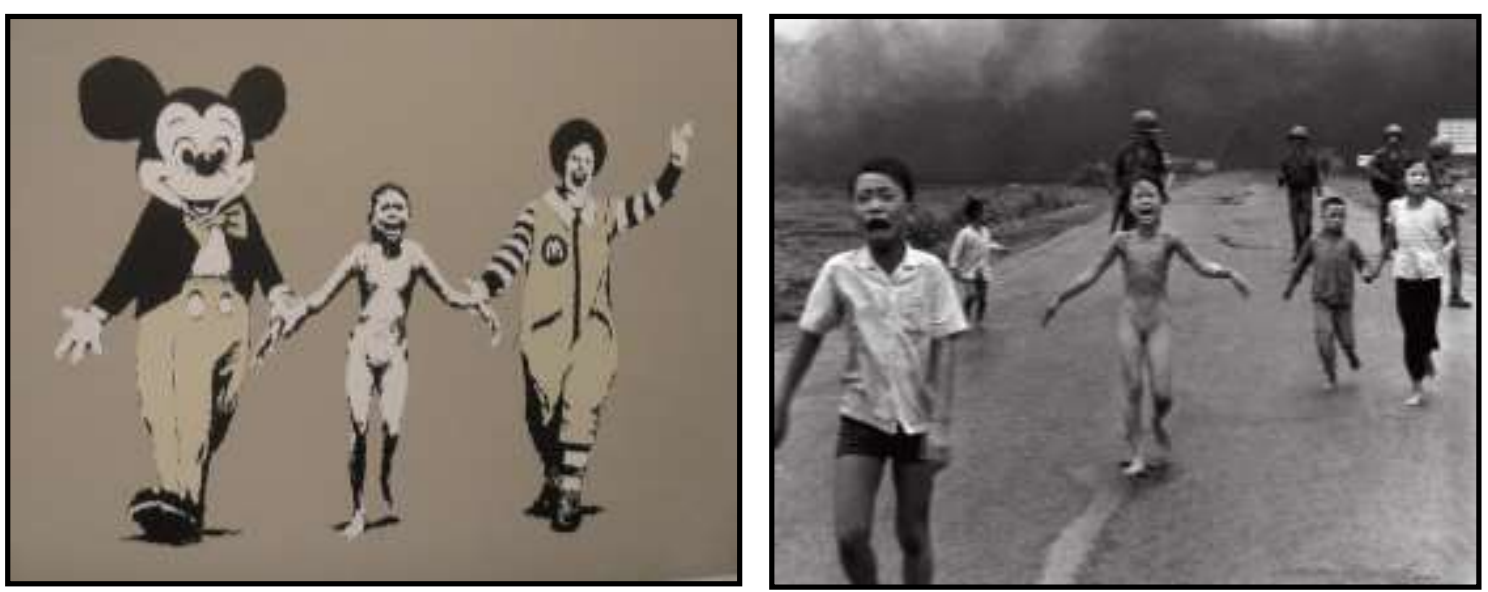

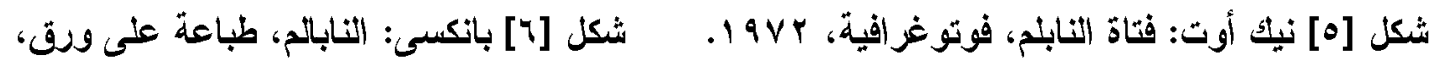

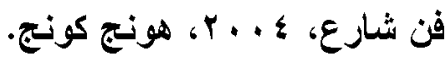

http://whitehotmagazine.com/articles /2008-banksy-schoeni-art-gallery/1288

\section{r. الادبية وانهيار القبم في أعمال الفن المعاصر:}

إن كل إنسان عامة، وفنان هذا العصر بصفة خاصة، حر بينطيع أن يعبر عن أفكاره ومفاهيمه كما بشاء وكيفما يناء. على عكس الفنان في الماضى؛ فقد كانت هنالك مبادىء تضعها

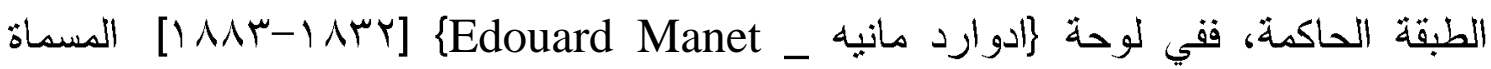
(غداء على العثب) شكل[V]، و التي " شو هدت لأول مرة في (معرض المنبوذين)، هذه اللوحة

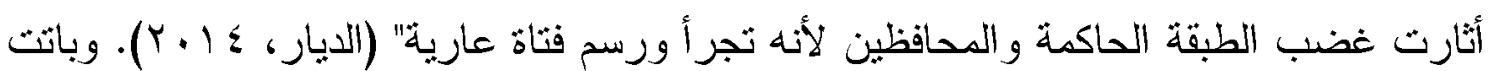

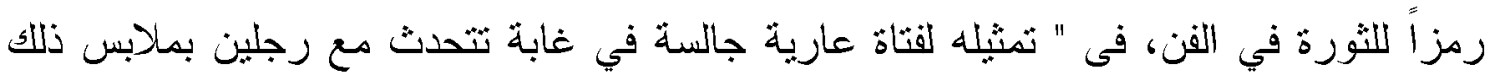

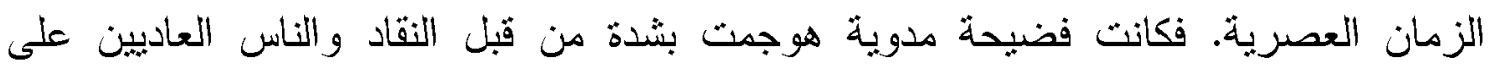

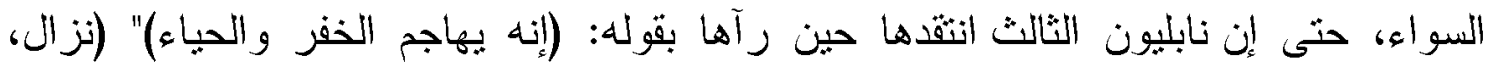


ص ONV). ورغم أن العمل يحمل جمالاً فنياً، إنما لكل عصر مفاهيمه وقيمه الفنبة والجمالية،

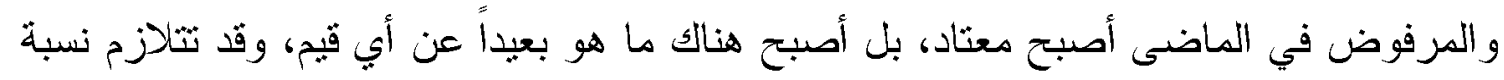

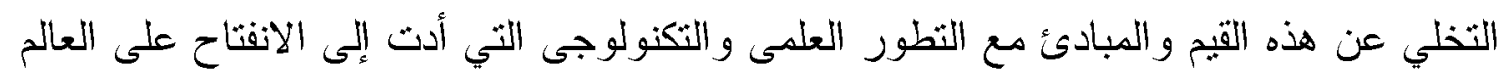

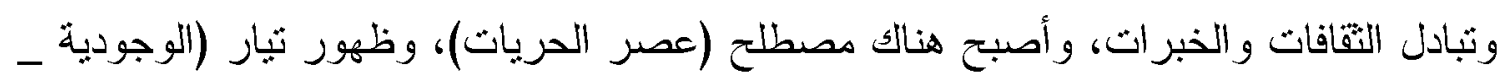

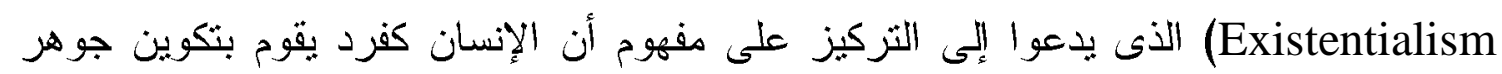

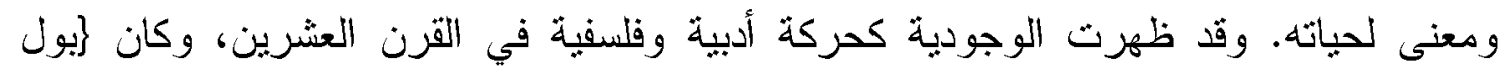

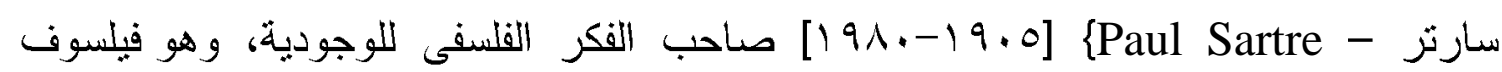
وكاتب تأثرث فلسفته بأهوال النزاعات والحروب خلال دوره كمناضل سياسى في صفوف

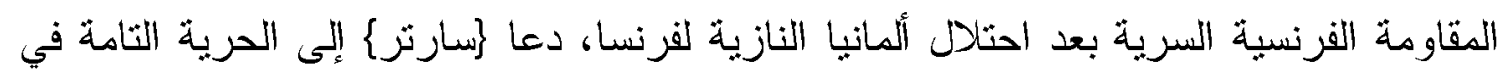

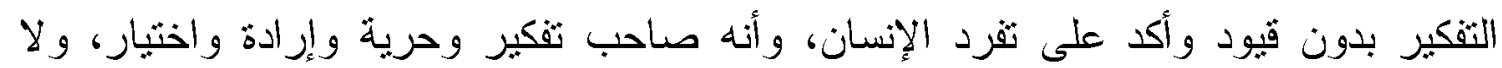
بحتاج إلى موجّه.

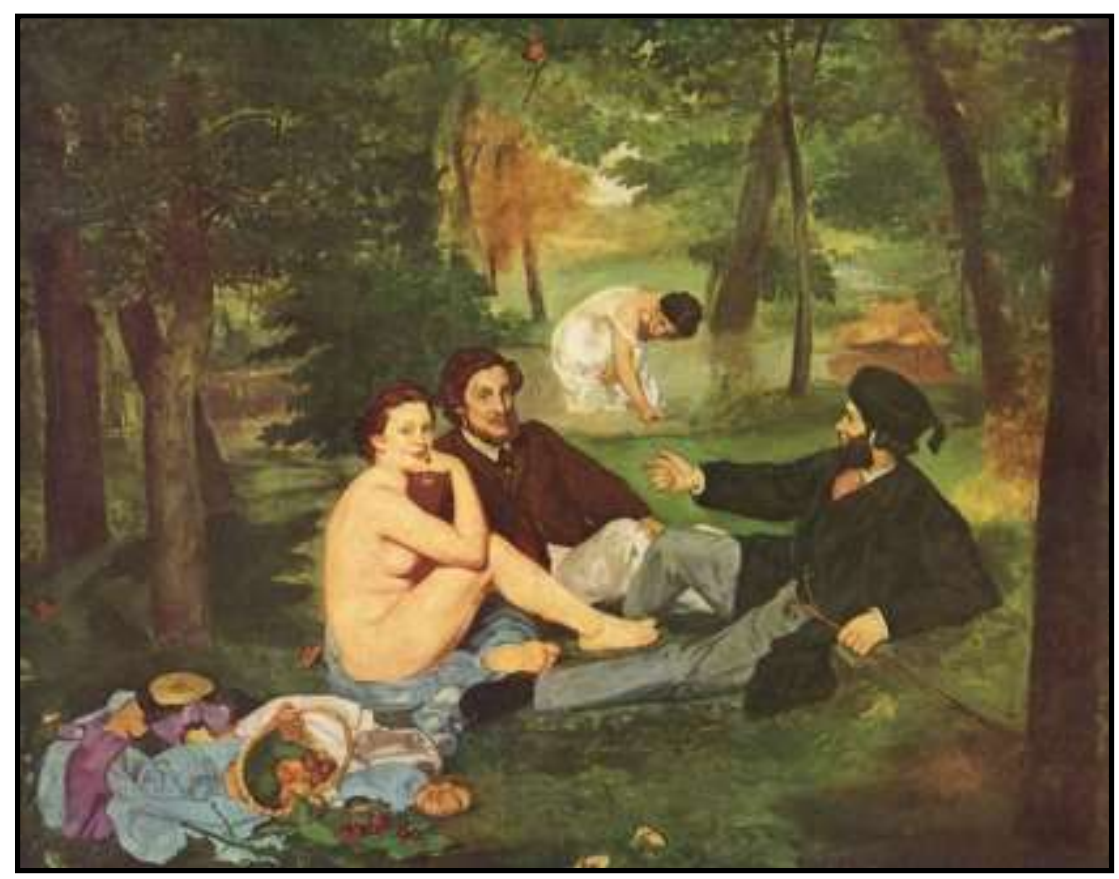

شكل [V] ادوارد ماتيه: غداء على العشب، فرنسا، سצ1A.

فأصبح الفنان المعاصر مسؤول عن أعماله بحريه، بختار ويقوم بنكوين أفكاره ومعتقاته، أنها

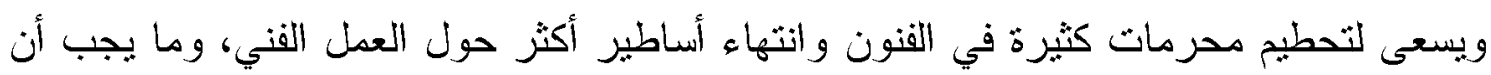

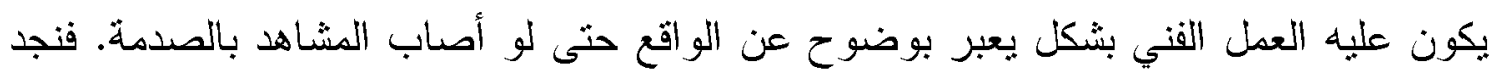

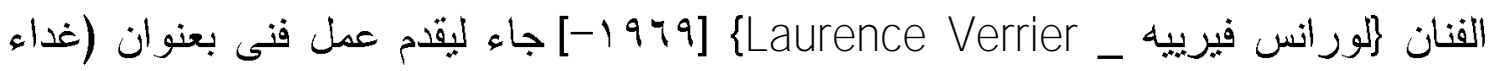


على العشب) شكل [^] و الذى قدمه بشكل ساخر وصادم وفيه نشويه للجمال، بغرض خلق حقائق

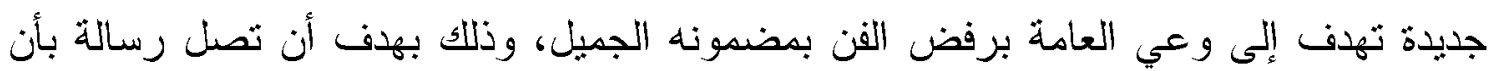

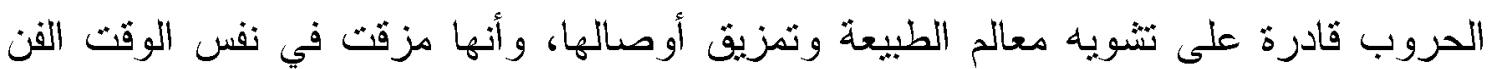
الجميل ليصبح عدمياً.

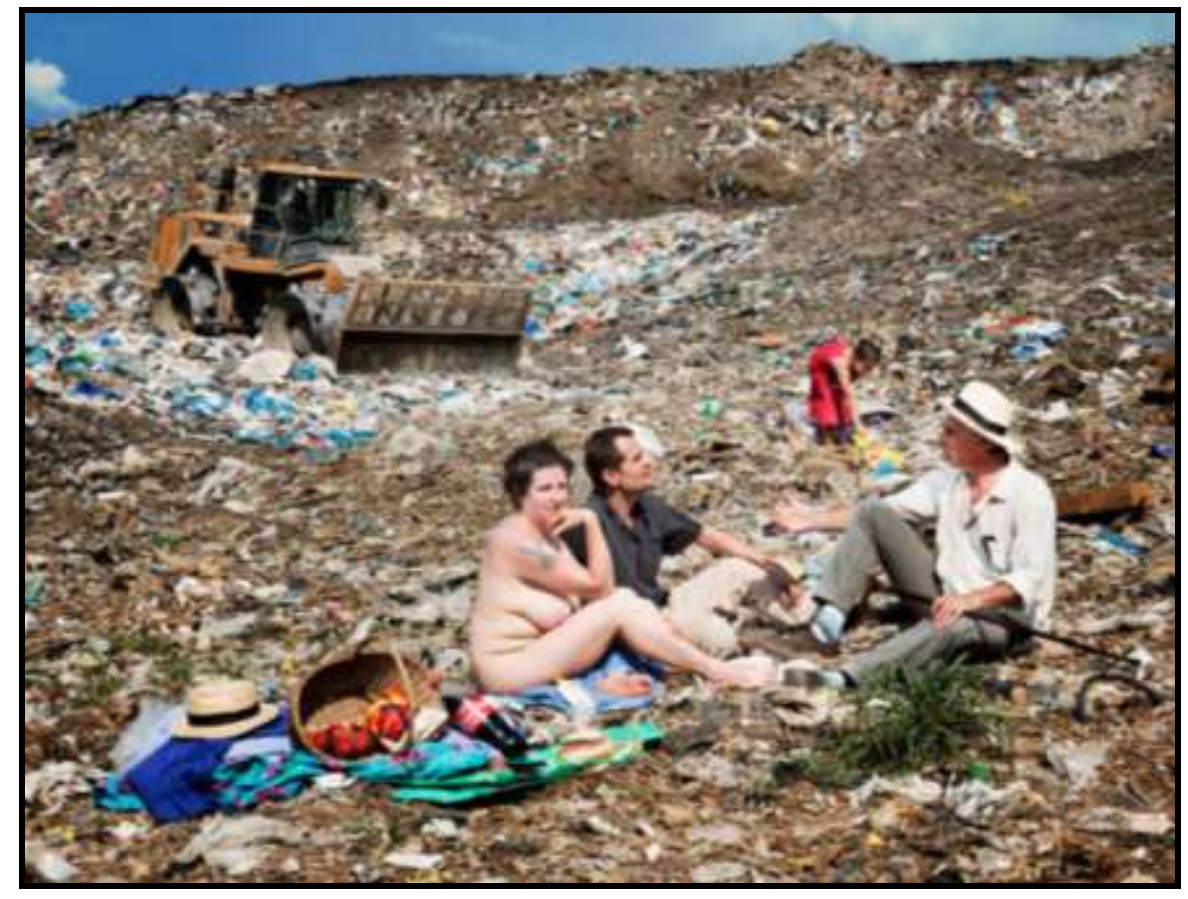

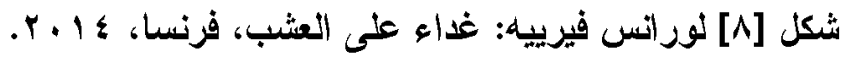
http://www.collectif6.net/index.html

أما الفنان \} جاك ـ دينوس تثابمان _ Jake \& Dinos Chapman فنجده في عمل بعنوان شكل(9)، قد عمد إلى تشويه (الجيوكندا) بهدف خلق رؤية (She Has Got a Hot Arse)

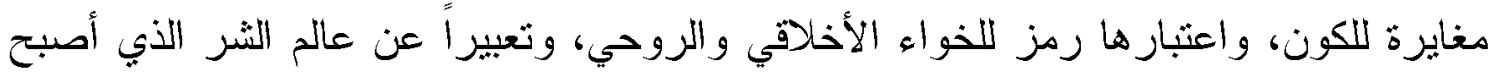

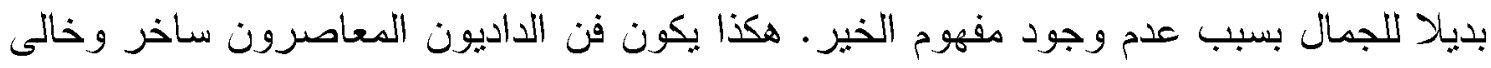

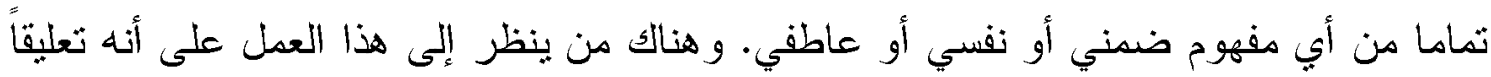
على الأحداث الأخيرة في (كيجالي) و (سربرنيتسا)، لذلك بدث وحشية ولنية ولأخلافية. 


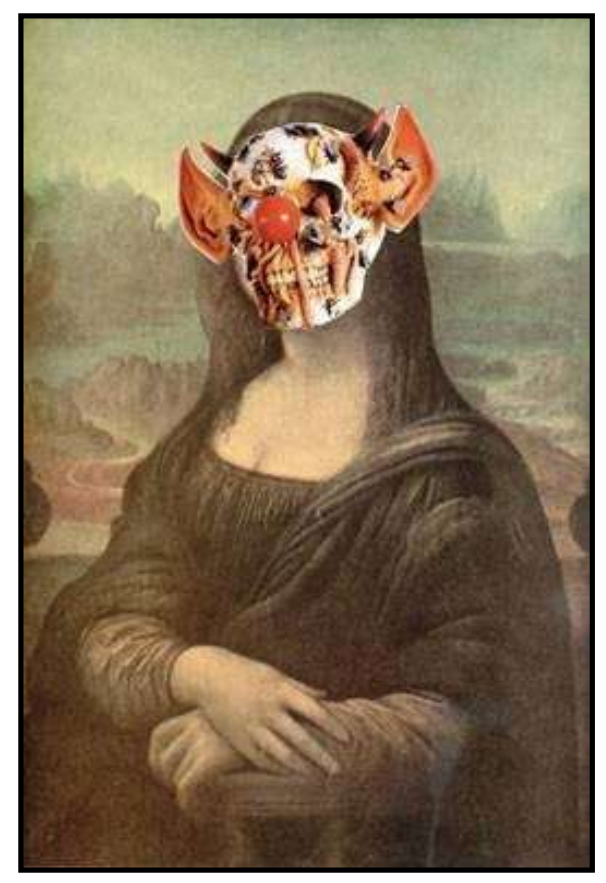

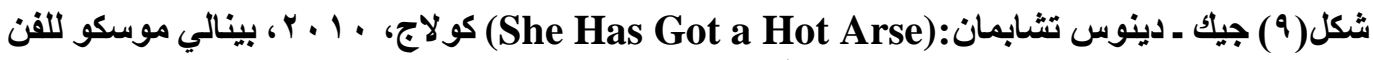

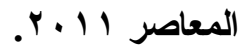

http://4th.moscowbiennale.ru/en/program/special_projects/dada_moscow.html و الفنانة المعاصرة \}سارة لوكاس _ SSara Lucas تثناول موضوعات خاصة بالموت و الجنس، وتقدمها بثكل غير وقور وبأحجام كبيرة. فتتطلت \}لوكاس\{ من واقع الحرية التي نؤمن بها، والتي تتخطى حدود القيم والأخلاق. وقد منلث \}لوكاس\{ المملكة المتحدة في أرقى الأحداث الفنبة العالمبة وهو بينالى فينسيا [0 · ب]. وفي عمل (السادي) شكل[ • 1] عبارة عن "سلسلة من أعمال النحت من الجص من أزواج من الأرجل المجزأة الثي ثم وضعها مع الأثاث المنزلي العادي كالكرسي والمكتب و المبولة، وهى بذلك تحاول أن تغير مفهوم تتاول الثكل الأنثوي الثقليدي في أعمال تاريخ الفن الذكوري على حد ثولها" ( Doherty, Mary).

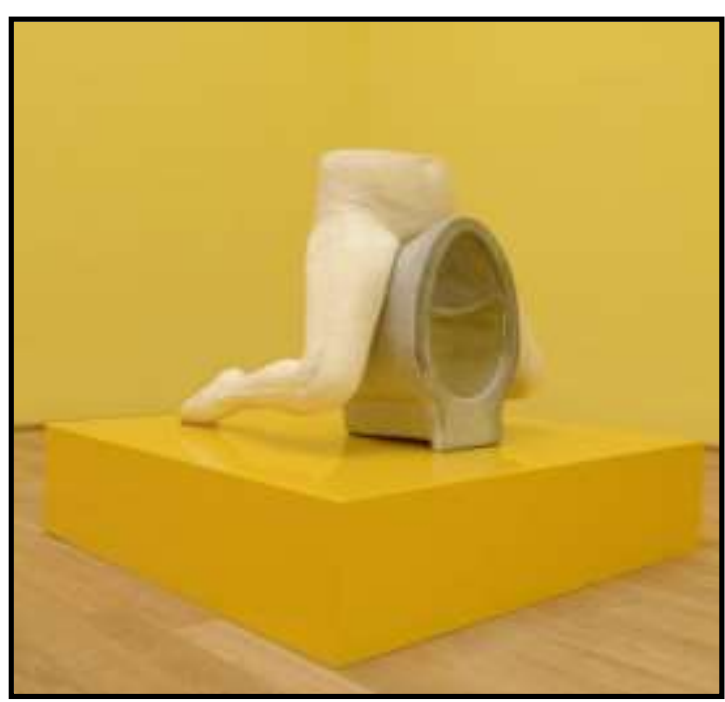

شكل] • 13] سارة لوكاس: السادى، الجناح البريطاني، بينالى فينسيا، 10 ـ ب. http://venicebiennale.britishcouncil.org/timeline/2015/image/1300

$$
\text { ir }
$$




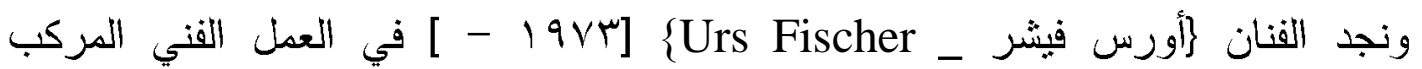

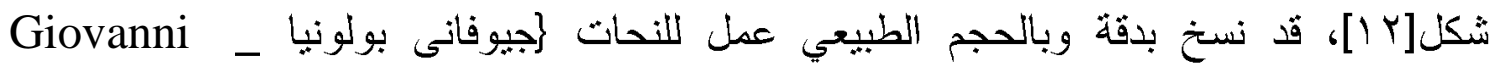
[Bologna و المواد الصلبة، وقد عرض هذا العمل ضمن فاعليات بينالى فينسبا عام [11.ب]. وفيه إلقاء الضوء على النفس أثناء التلاشى وقت انتظار ذوبان الثمع، ليعطي المشاهد دقائق من المجد الزائل، واستكنداف التاريخ الفردي والجمعي في العالم الافتراضي، والمشابهة في تمثيل نظلل

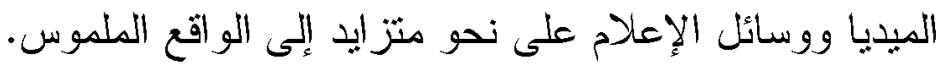

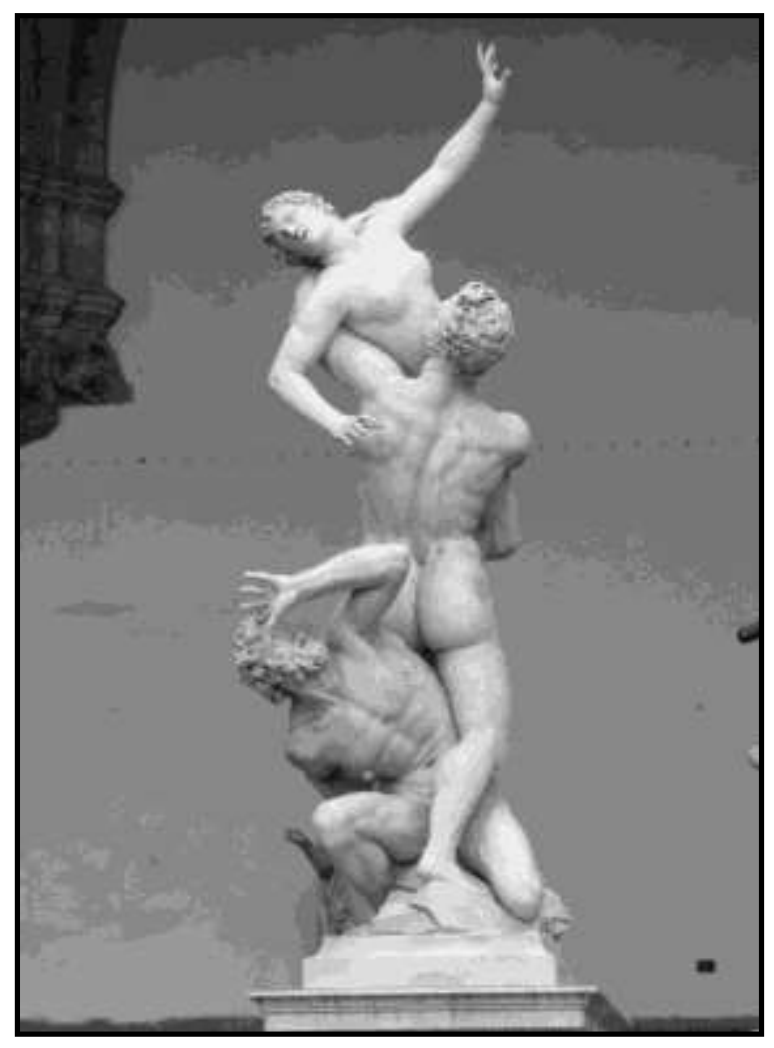

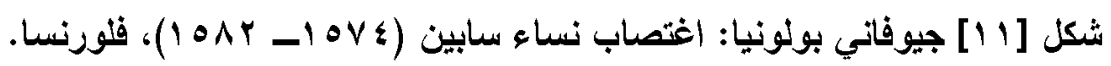

لقد أراد (فيشر) من خلال هذا العمل التعبير عن عملية الثيخوخة، والتي يؤكد أنها لا نؤثر

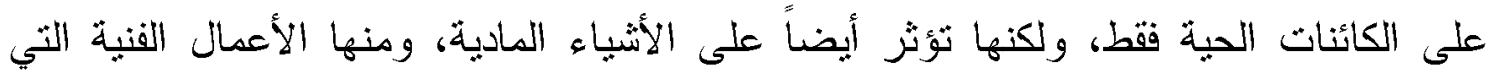

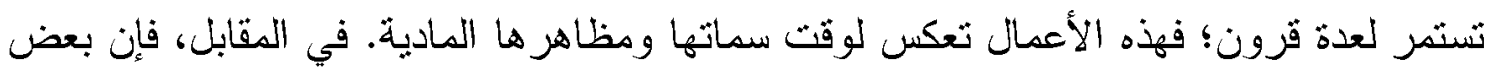

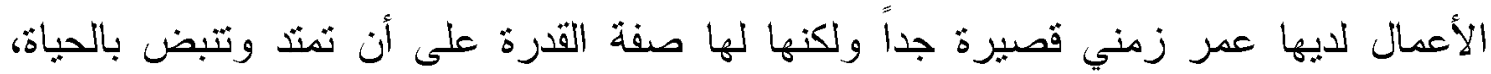

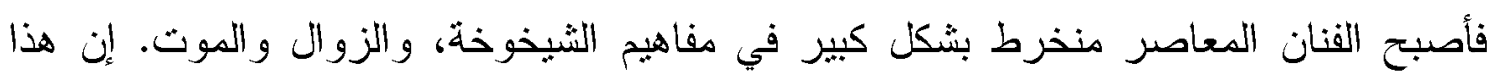

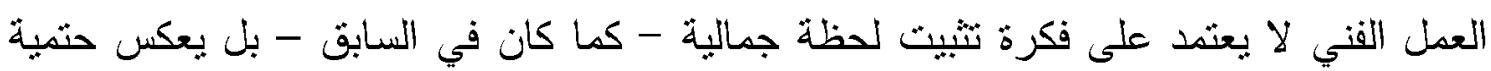

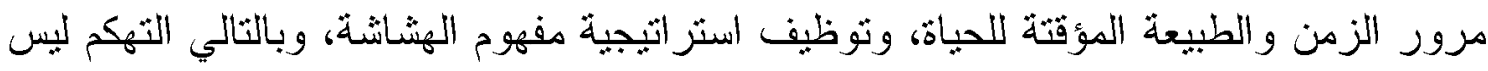


فقط على زوال القيم الجمالية، ولكن الأهم من ذلك، هو إدراك تدهور الخطاب المبنافيزيقي

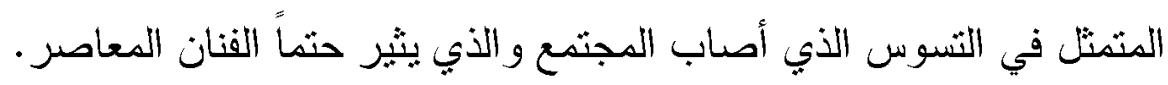
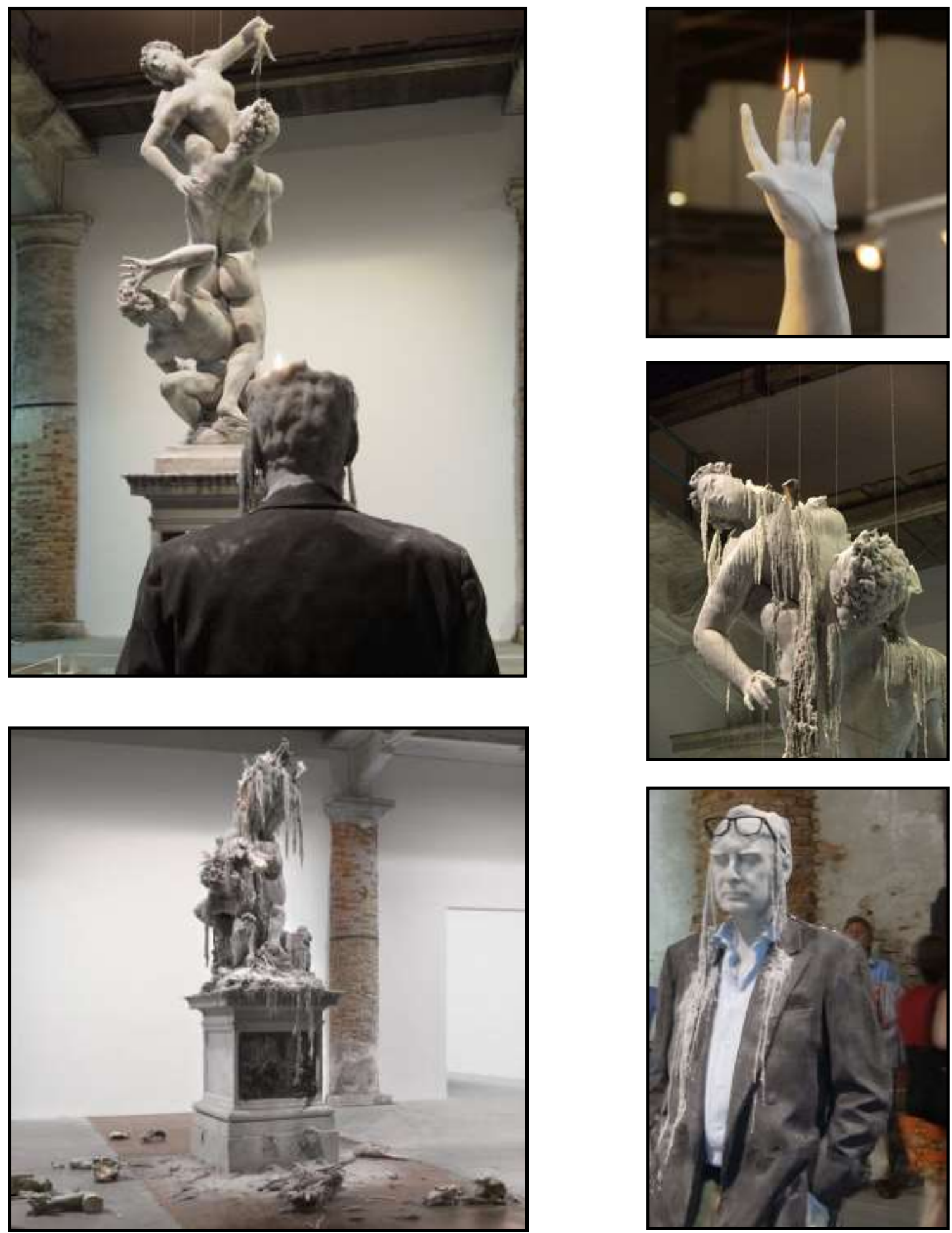

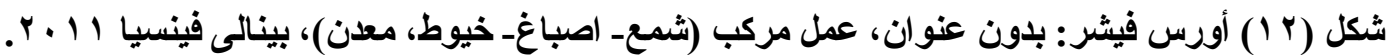




\section{ـ. الادبية وتحى الأوق الجماهبرى ومعابير الجمال:}

من خلال العرض السابق تتضح العلاقة الطردية التبادلية بين الفعل ورد الفعل، المنمثلان

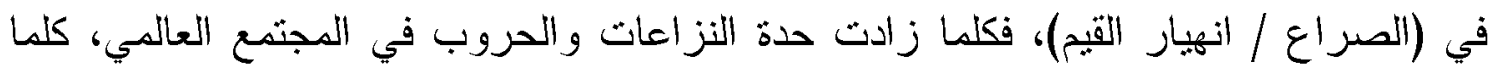
زادت ثورة الفنان وعلا صونه وشحذ أدواته للتعبير عن ثلاك المآسي، لا يلقى بالاً إلى ذوف الجمهور، بل بعتبر نفسه هو المتحدث بلسان مجتمعه ويئته بمفردات ولغة الفن، فيتحرك بدون

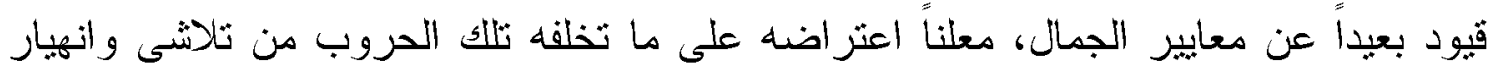

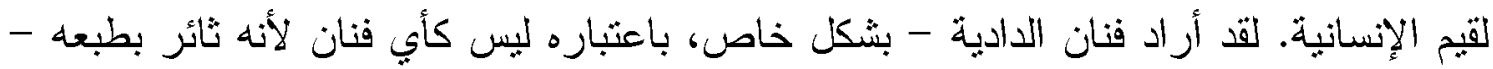

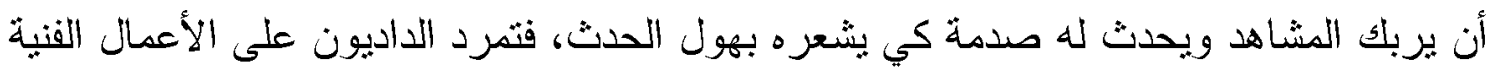
التي تعبر عن العواطف والتي تسبطر على الذوق العام، وعرضوا مشاهد غريبة وموضوعات

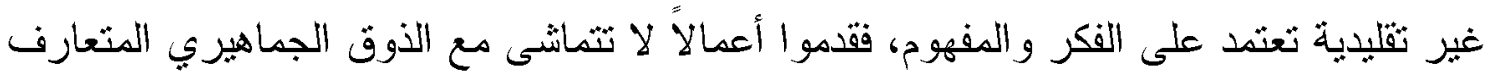

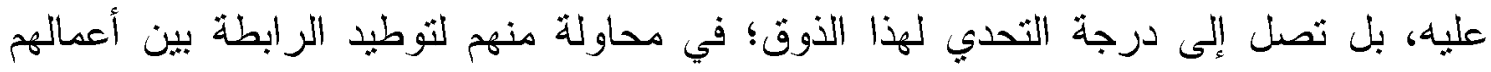

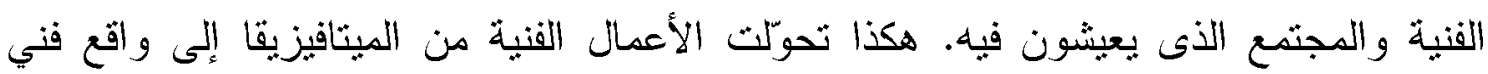
صادم ذو طابع مفاهيمي.

لكل فن من الفنون أصول وقو اعد وجمال يختص به، وهو نتاج فنانين ونقاد وباحثين

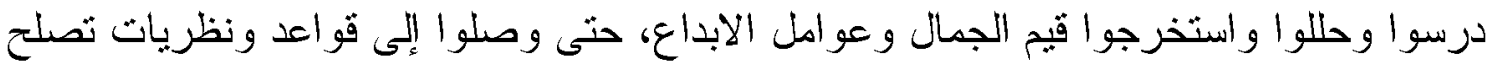

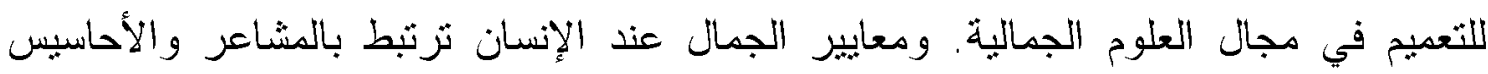

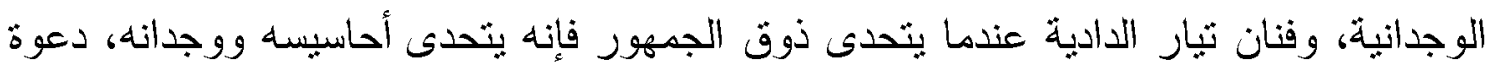
منه إلى الانتباه وأن إعلاء دور العقل إلى جانب الوجدان، هو اللغة المناسبة لقراءة وفهر دأنه

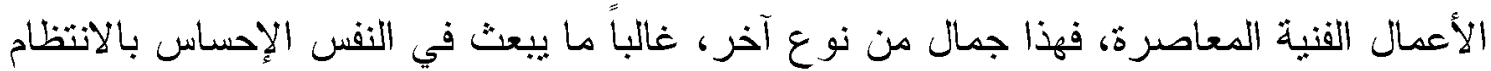

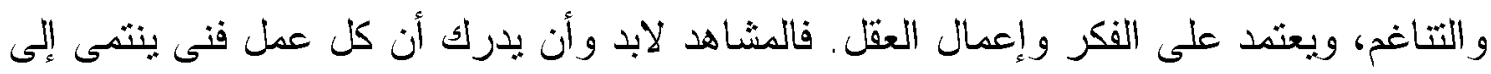
ثبار الدادية بعد بمثابة صفعة على وجه كل من هو وراء تلك النزاعات. وليس المقصود العمل الفني في حد ذانه، ولكن المقصود هو إعادة طرح السؤال حول طبيعة العمل الفني، وربما إعادة

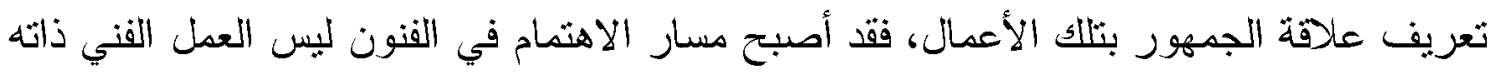
ولا حتى الحرفية أو الإبداع في صنعته، ولكن فيما يقدمه من أفكار وتصورات وتساؤلات ومفاهيم جديدة، باعتباره موقف بصري يعكس حقيقة واقعية نحاكي الإحساس العقلي قبل العاطفة

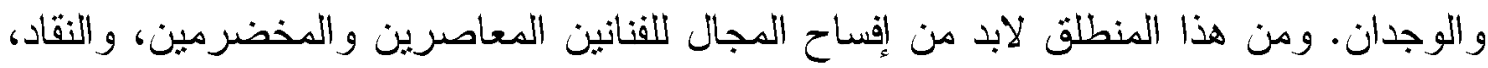
و الباحثين والمؤرخين في تحديث وإعادة النظر في معايير الجمال في الفنون النتكيلية

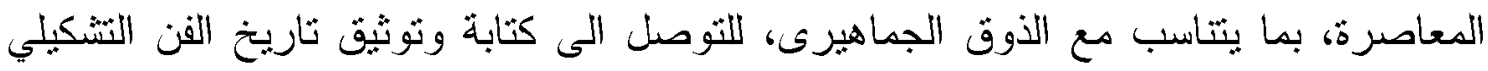
المعاصر بشكل مفيد ومؤثر. 


\section{نتائج وتوصبات البحث}

أولاً: نتائج البحث:

- - إن كثير من أعمال الفن المعاصر تحثوى فى مضدونها على مظاهر وسمات النزعة الدايةا. - تيار الدادية هو محور التغير إلى فنون ما بعد الحداثة، مثلما كانت الانطباعية هي محور التغير إلى فنون الحداثية.

- الدادية الجديدة هي محور التغير الى الفن المعاصر، مثلما كانت الدادية هي محور التغير الى فن ما بعد الحداثة.

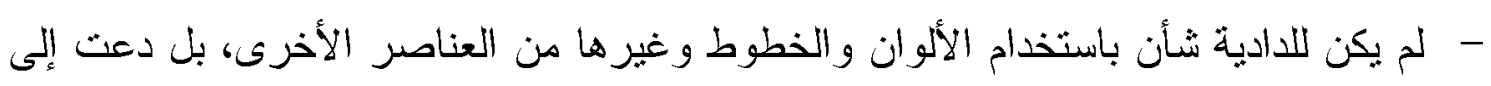
أن الأشباء المصنوعة هي في حد ذاتها فن أبضناً، ولعلها تحل محل اللوحة.

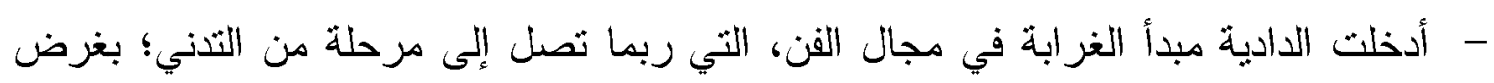
إحداث صدمة للمثاهد.

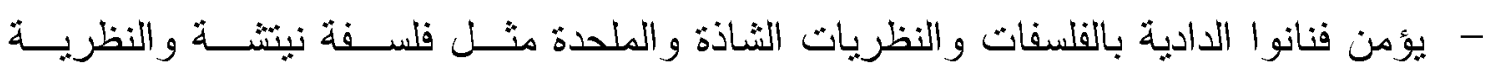
الوجودية.

- ظهور الدادية دائماً ما يكون نتيجة لظروف سياسية واجتماعية فهي وليدة المتتاقضات. - كان للأحداث السياسية المتلاحقة و النغيرات السريعة دور فعال في حث الفنان على البحث عن لغة تشكيلية جديدة نلائم روح هذا العصر. وبذلك أصبحت الوسائط المعاصرة هي

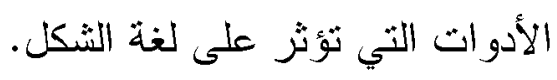

ثنانياً: التوصيات:

- - دراسة مزيد من الاتجاهات الفنية الأخرى غير الدادية، والثي تثأثز بــالتغير ات السياســبة و الاجثماعية و الثنافية.

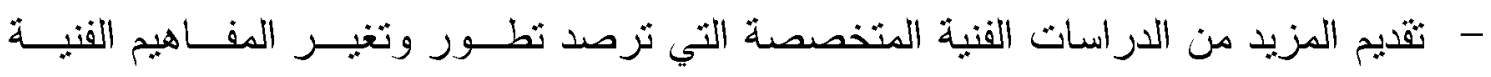
و الجمالبة الأخرى، والتي تثعلق بنيار الدادية؛ والتي بدورها تفيد في تتمية التقافة البصــرية والارثقاء بمستوى التذوق و القدرة على النقد. 

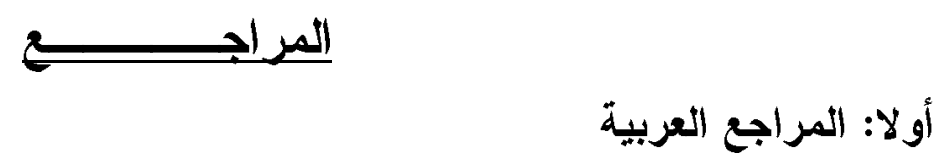

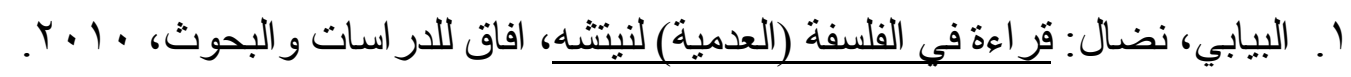
http://aafaqcenter.com/post/448

http://www.addiyar.com/article

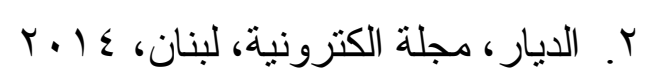

http://fenon.com

$$
\text { r. أمهز ، محمود: الفن التشكيلى المعاصر، دار المثلث، بيروت، } 1911 .
$$

$$
\text { ؟. عطية، محسن: التفسير الدلالى للفن، عالم الكتب، V... V. }
$$

•. عطية، محسن: القيم الجمالية في الفنون النتكيلية، دار الفكر العربى، الطبعة الأولى

$$
\text { 7. محمود البسيونى: الفن في القرن العشرين، دار المعارف، القاهرة، سب919. }
$$

V. نز ال، نهيل: إدو ار مانيه، مجلة العمارة و الفنون التشكيلية و الزخرفية، المجلد السابع عشر ،

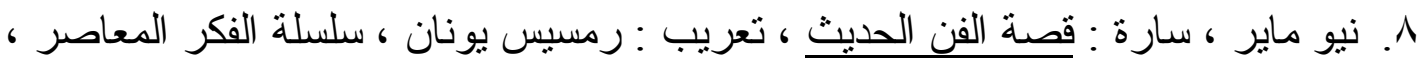

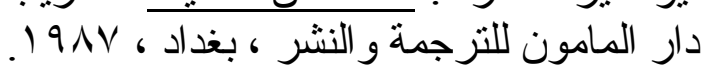

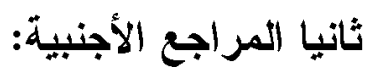

9- Baro, Hanna: Concepts of Transience and Temporality in 20th Century Art, http://www.khi.fi.it/4828166/baro_concepts

10- Bray, Tim: Eden Images, 2015.

https://tbrayphotgraphy.wordpress.com/contexual-studies-3

11- Doherty, Mary: Sarah Lucas | I SCREAM DADDIO http://venicebiennale.britishcouncil.org/timeline/2015

12- Domus Magazine:

http://www.domusweb.it/en/art/2011/06/06/illuminations.html

13- Whitney Museum of American Art, New York, 2015. http://collection.whitney.org/object/425

14- Wolf, Justin: The Art Story, Neo-Dada, 2015

http://www.theartstory.org/movement-neo-dada.htm 


\section{Now}

يشهُ الواقع الاجتماعى والسياسى في العالم اليوم الكثبر من النزاعات والصراعات

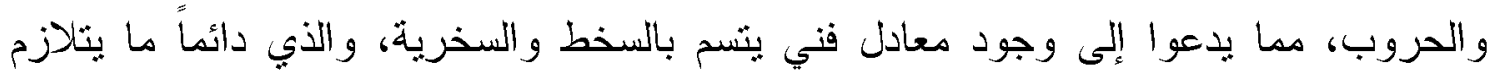

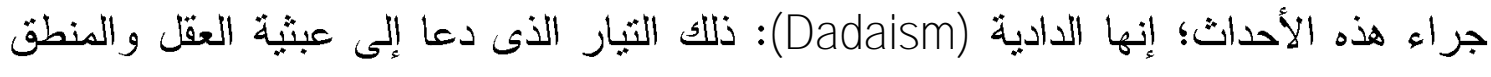

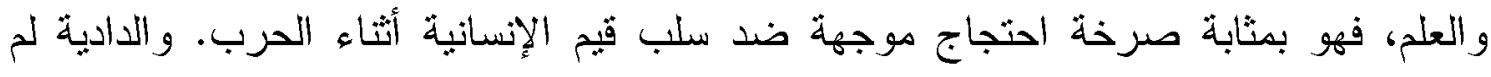

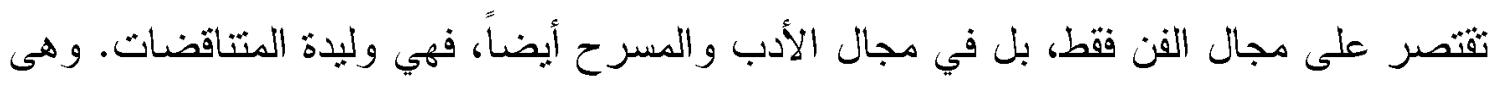

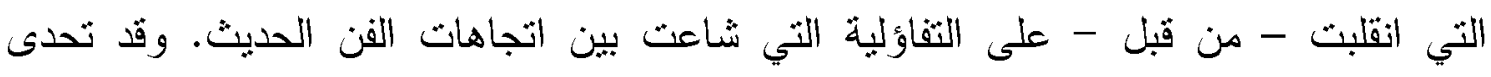

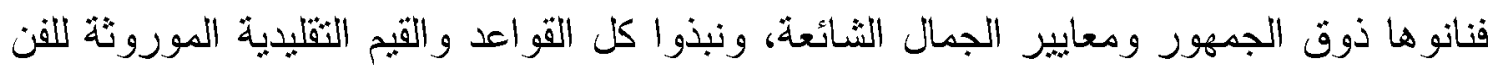

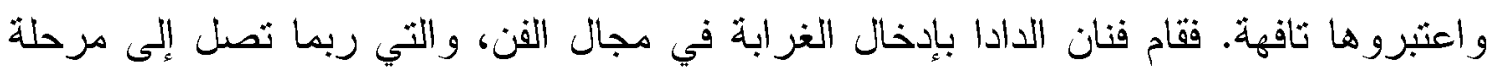

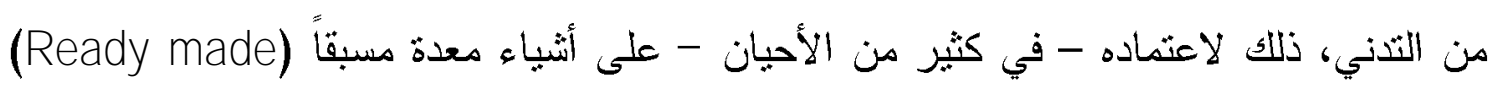

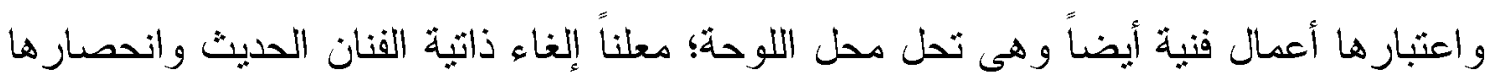

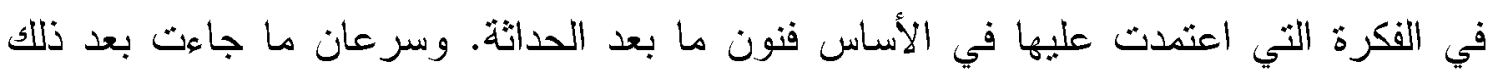

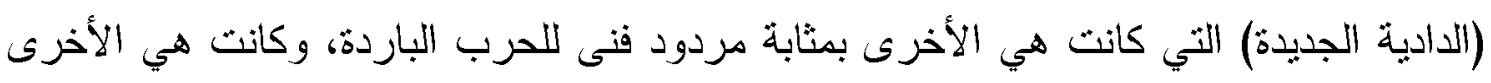

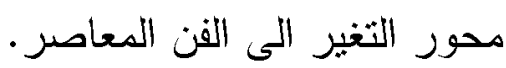

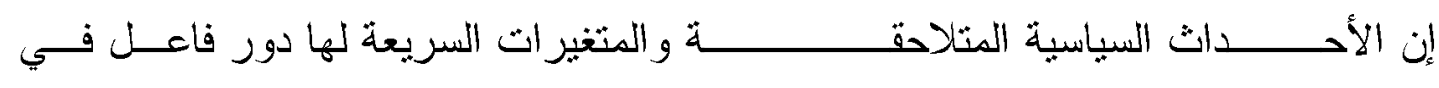

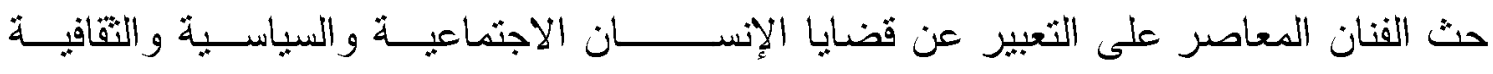

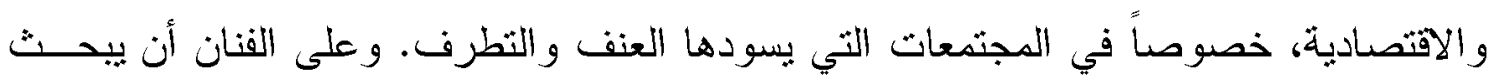

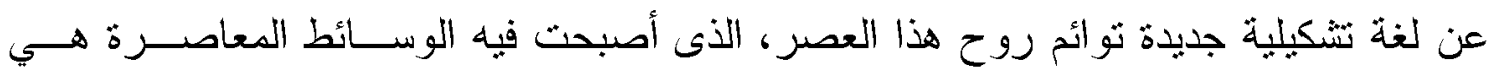

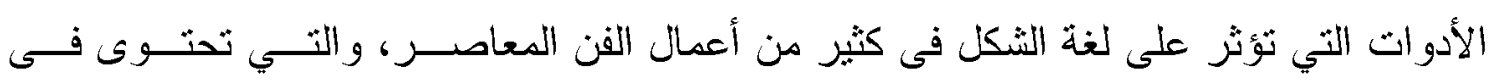

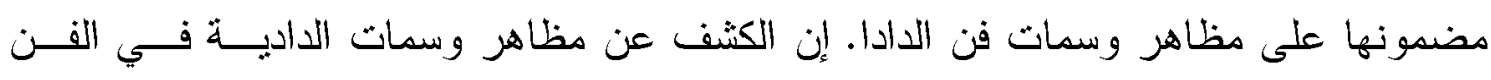
الدعاصر يزيد فى التعرف على اللغات الو افذة والمستحدثة في مجال الفن؛ للوقوف على الكي المعايير المسنديثة أيضاً في النقد الفني وعلم الجمال. 


\begin{abstract}
:
The reality of social and political in the world today is witnessing a lot of disputes and conflicts and wars, which advocated the existence of equivalent technical characterized by discontent and cynicism, which always goes hand in hand as a result of these events; it is Dada: This movement, which called for the absurdity of reason and logic and science, It serves as a cry of protest against the looting of humanitarian values during the war. Dada was not limited to the field of art only, but in the field of literature and theater also, it is the result of contradictions. It overturned - in the past - optimistic which the spread between modern art. Artists have challenged the public tastes and common standards of beauty, and renounced all the rules and inherited traditional values of art and they considered trivial. Dada artist so the introduction of strangeness in the field of art, which may reached the stage of degradation, So for adoption - is often - the prepared in advance objects (Ready-made) and also considered works of art and supersedes and replaces the painting; Declaring the abolition of artist Subjectivity and limited only in the idea, which was adopted in basis for postmodern art. And quickly came after it (the new Dada) which is a response other reaction artistic of the Cold War, and the other is to change the focus of contemporary art.
\end{abstract}

The slipstreamed political events and rapid changes have an active role in urging the contemporary artist to express their social, political, cultural and economic rights issues, particularly in societies dominated by violence and extremism. And that the role of the artist looking for a new plastic language in order to harmonize the spirit of this age, Which has become a contemporary media Which has become a contemporary media are the tools that affect the form language in many works of contemporary art, Which Containing in its content on the manifestations of and attributes for Dada art. The disclosure of manifestations of and attributes Dada in contemporary art Cause an increase in knowledge of expatriate language and the updated in the field of art; to stand on the updated standards also in art criticism and aesthetics.

Key words: Dadaism - contemporary art. 